\title{
Ventricular Fibrillation during Colonoscopy: a Case Report -Colonoscopy in High-risk Patients Should be Performed with ECG Monitoring
}

\author{
Takuhiro Ugajin ${ }^{1}$, Hiroyuki Miyatani ${ }^{1}$, Shin-ichi Momomura ${ }^{2}$, Masamitsu Sanui ${ }^{3}$, \\ Yoshiyuki Nakashima ${ }^{1}$ and Yukio Yoshida ${ }^{1}$
}

\begin{abstract}
While ventricular premature contractions have been noted during colonoscopy (CS), ventricular fibrillation (VF) is rare. We recently had a patient who developed VF during CS and recovered without any sequelae despite severe complications after cardiopulmonary resuscitation (CPR). If electrocardiogram (ECG) monitoring had been done during CS, a direct current shock defibrillation could have been accomplished and prevented complications. CS in high-risk patients should be done with ECG monitoring.
\end{abstract}

Key words: colonoscopy, high-risk patients, complication, ventricular fibrillation, arrhythmia, heart failure

(Inter Med 47: 609-612, 2008)

(DOI: 10.2169/internalmedicine.47.0559)

\section{Case Report}

A 74-year-old woman was treated with warfarin (PT-INR 2.4) following mitral valve replacement (MVR) 8 years prior to CS. She had no dyspnea on walking and activities of daily living (ADL) were preserved despite chronic right heart failure. Five months previously, normocytic normochromic anemia (RBC $259 \times 10^{4} / \mu \mathrm{l}, \mathrm{Hb} 8.6 \mathrm{~g} / \mathrm{dl}$, Ht 26.8\%) was found. Fecal occult blood tests were positive for Guaiac test but negative for human hemoglobin. Her jugular veins were distended and marked enlargement of the right atrium (RA) was suspected based on chest X-ray findings (CTR; 70\%) (Fig. 1). Electrocardiogram (ECG) showed atrial fibrillation and right axis deviation (Fig. 2).

Echocardiogram showed left ventricular ejection fraction of $58 \%$ and mean pressure gradient (PG) of $4.1 \mathrm{mmHg}$ across the prosthetic mitral valve. RA was markedly enlarged and right ventriclar systolic function was reduced. Massive tricuspid regurgitation (TR) and moderate aortic stenosis (AS) (mean PG; $38.2 \mathrm{mmHg}$ ) were present. Upper G-I bleeding was not detected by esophago-gastro-duodenal endoscopy. Lower G-I bleeding was therefore suspected and a CS was performed with administration of glucagon $1 \mathrm{mg}$ before the procedure. She had a redundant sigmoid colon. When the colonoscope had been inserted $55 \mathrm{~cm}$ to the sigmoid descending junction, she suddenly complained of abdominal pain, exhibited convulsive movements with her eyes turned upward, and lost consciousness. The colonoscope was rapidly removed but her pulse became weaker and finally could not be felt. She was connected to the ECG and VF was detected. She was defibrillated three times with 360 J (Fig. 3A, B). Blood tests showed sodium $142 \mathrm{mmol} / \mathrm{L}$, potassium $4.1 \mathrm{mmol} / \mathrm{L}$, urea $14 \mathrm{mg} / \mathrm{dl}$, and creatinine $0.67 \mathrm{mg} /$ dl. After ventricular defibrillation, she was transferred to the coronary care unit (Fig. 4).

Following cardiopulmonary resuscitation (CPR), she developed shock lung and hypoxic cerebral damage. She was intubated and treated with hypothermia. That night, she had an intra-abdominal hemorrhage and developed shock. Laparotomy was done the following morning. The colon was intact but there was oozing of blood from the surface of the liver, possibly a complication of cardiac massage. Hemorrhage was controlled with compression, use of oxidized re-

${ }^{1}$ Division of Gastroenterology, Saitama Medical Center, Jichi Medical University, Saitama, ${ }^{2}$ Division of Cardiovascular Medicine, Saitama Medical Center, Jichi Medical University, Saitama and ${ }^{3}$ Division of Anesthesiology and Critical Care Medicine, Saitama Medical Center, Jichi Medical University, Saitama

Received for publication August 25, 2007; Accepted for publication December 25, 2007

Correspondence to Dr. Takuhiro Ugajin, tugajin@omiya.jichi.ac.jp 
generated cellulose, and electrocautery. Following surgery, however, she developed DIC, ventilator-associated pneumonia, and septic shock. She gradually recovered but nonsustained ventricular tachycardia (NSVT) was detected by ECG monitor. She was started on amiodarone $100 \mathrm{mg}$ /day but KL-6 increased. So amiodarone was discontinued. Enalapril maleate $1.25 \mathrm{mg} /$ day was added for cardioprotection. NSVT and ischemic ST change were not detected by Holter ECG. She was discharged about 10 weeks following $\mathrm{CS}$ and CPR.

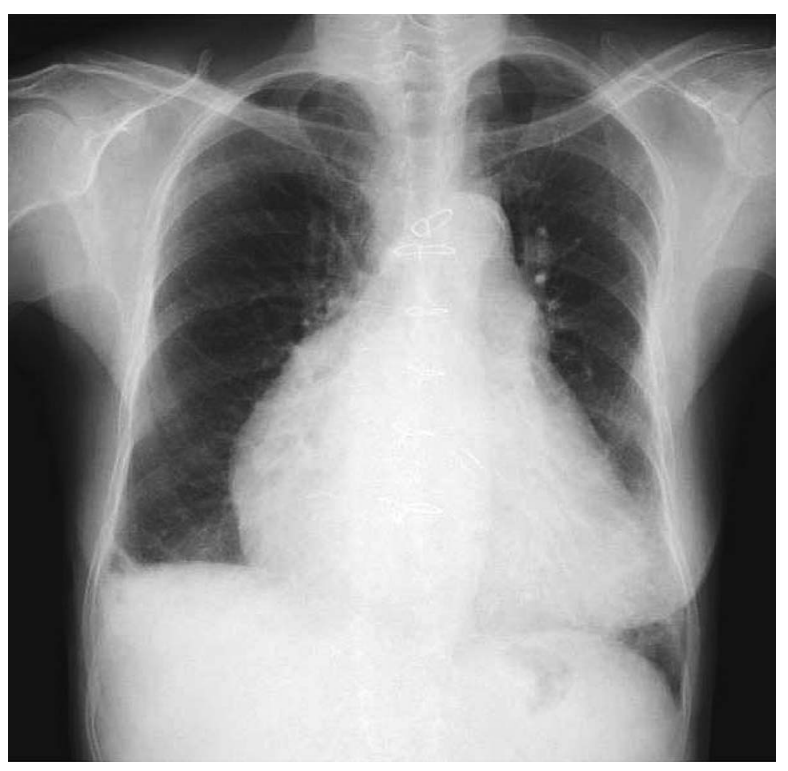

Figure 1, Chest X-ray before colonoscopy showed cardiomegaly due to right heart failure.

\section{Discussion}

Many CS are now performed without proper thought paid to possible risks. Major cardiovascular complications that may occur during CS are bradycardia due to vagotony and sinus tachycardia induced by vagolytic premedication, which may predispose to myocardial ischemia due to augmented cardiac workload. Severe arrhythmias are rare, however, although there are some reports of VF during CS $(1,2)$. VF is a major cause of death in patients with congestive heart failure $(3,4)$. The exact cause of VF in this patient is unknown. Pain during CS may have stimulated the Valsalva maneuver and the elevated intrathoracic pressure decreased pulmonary circulation and caused transient pulmonary hypertension $(\mathrm{PH})$, which in the presence of severe TR, reduced the cardiac output (5). Dehydration and vagotony associated with distension of the gastrointestinal tract might have induced transient hypotension and subendothelial ischemia, which contributed to VF. It is also possible that AS, which poses a risk for preoperative complications, although not severe in our patient, may have been contributory (6).

Distention of hollow abdominal organs in dogs can decrease left coronary artery blood flow (7). Emotional stress may alter electrical instability of the myocardium resulting in a lowered threshold for ventricular fibrillation (8) and emergence of potentially lethal arrhythmia. The possible effects of enalapril on right heart dysfunction remain speculatory, although preload reduction by a venous dilatory effect (9) is possible.
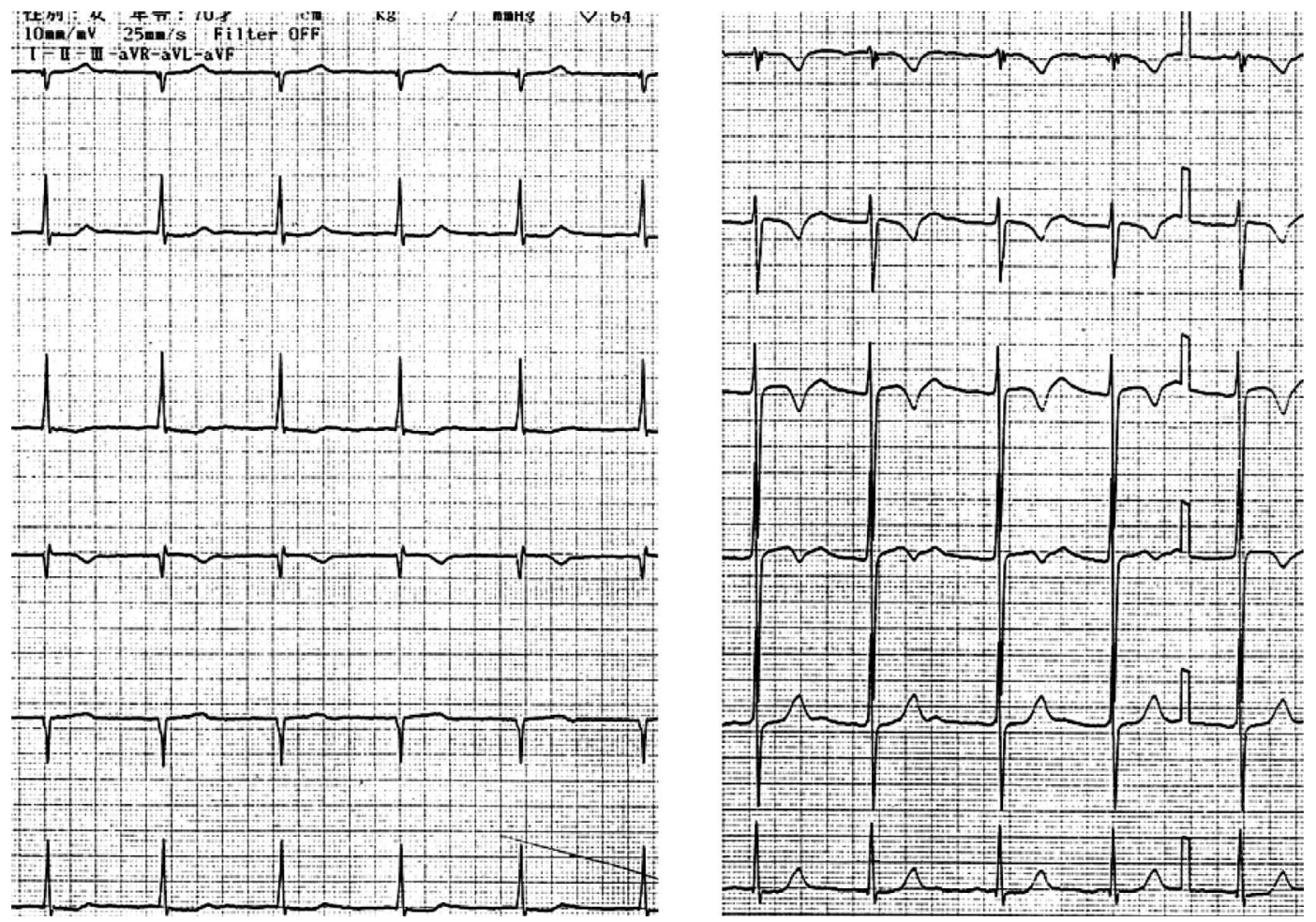

Figure 2. Twelve lead electrocardiogram before colonoscopy showed atrial fibrillation and right axis deviation. 
A

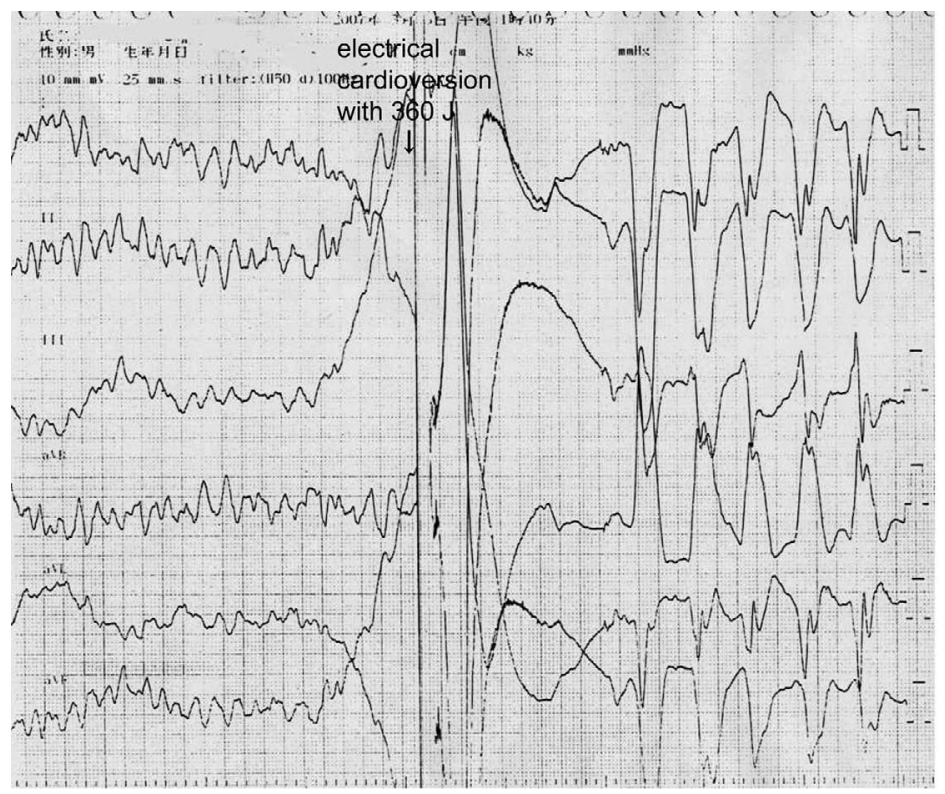

B

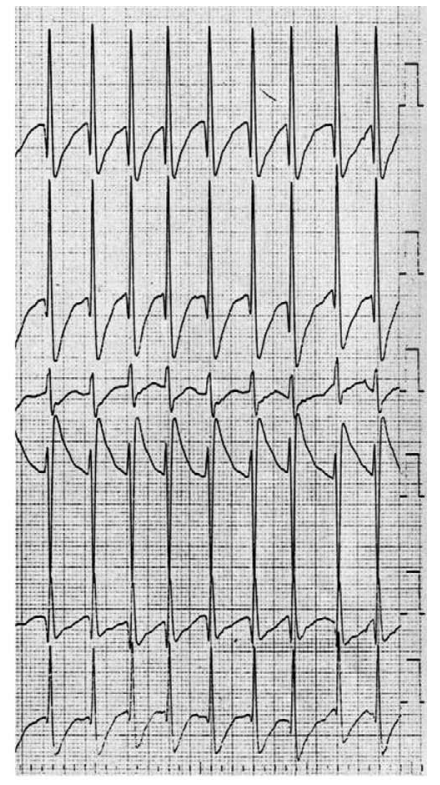

Figure 3. A: Electrocardiogram demonstrated ventricular fibrillation with electrical cardioversion $360 \mathrm{~J}$. B: (not continuous) and rapid atrial fibrillation after electrical cardioversion.

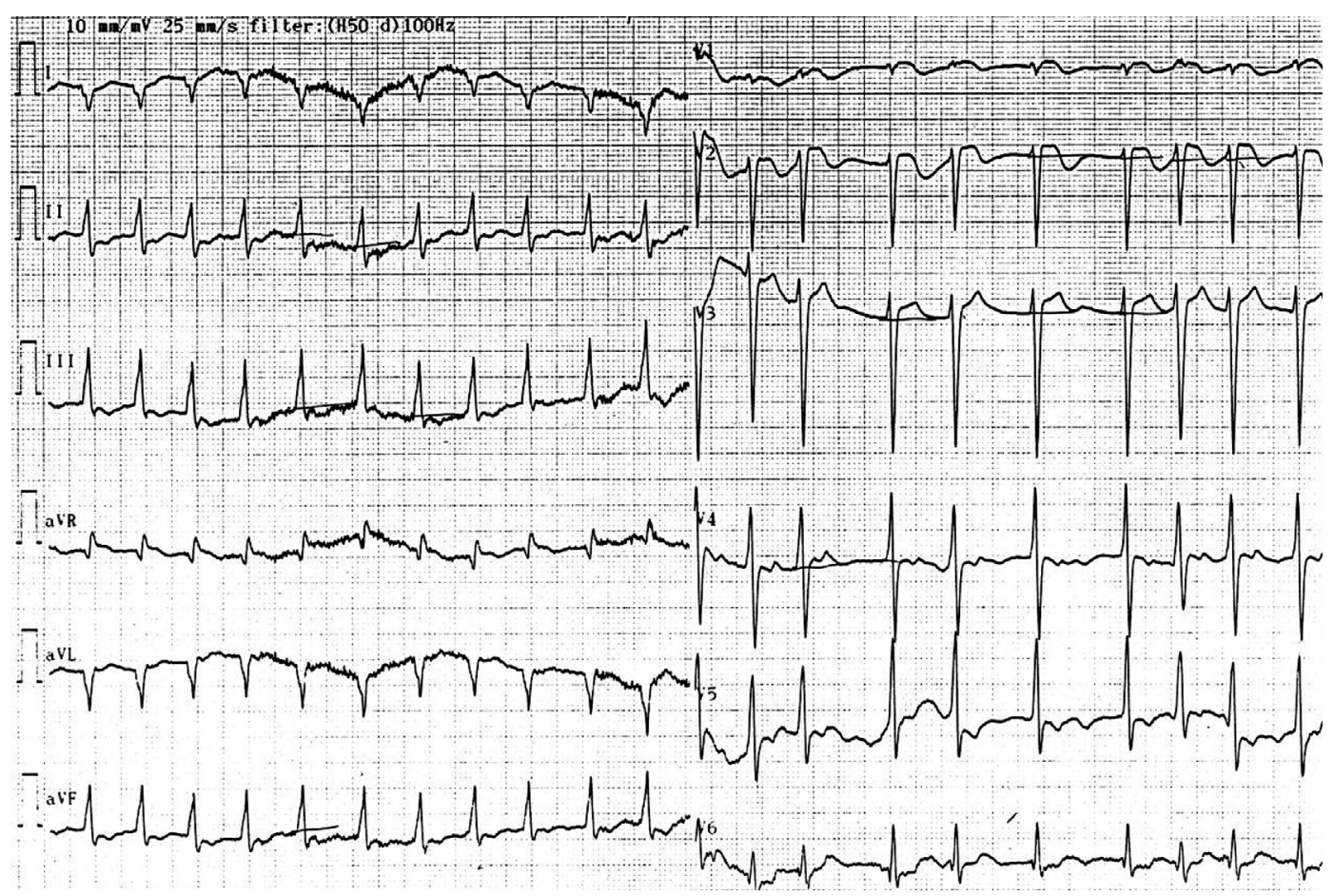

Figure 4. Twelve lead electrocardiogram taken in the coronary care unit 20 minutes after electrical cardioversion.

There was no indication for an implantable cardioverterdefibrillator in this patient. Because VF was mainly due to CS and prevention was considered feasible and likely to substantially reduce the risk of recurrent VF.

Although CS is generally thought to be a low risk procedure, dehydration, hypotension due to vagotony, catecholamine release stimulated by fear and pain may induce cardiac events such as acute myocardial infarction and lethal arrhythmia. ECG monitoring is necessary to distinguish between vagotony and a cardiac event such as VF as a cause of faintness during CS. If ECG had been monitored during CS, an immediate direct current shock could have restored basal AF rhythm without any other complications. We should estimate the level of risk for cardiac events in patients who undergo CS and use ECG monitoring during CS in these patients at high risk, such as patients with known cardiac disease and those with documented arrhythmias. 


\section{References}

1. Norman JC, Aronow A, Aronow S, Judge RD. Iatrogenic ventricular fibrillation during proctosigmoidoscopy in patient with complete heart block. Ann Surg 163: 306-310, 1966.

2. Davison ET, Levine M, Meyerowitz R. Ventricular fibrillation during colonoscopy: Case report and review of the literature. Am J Gastroenterol 80: 690-693, 1985.

3. Bigger JT Jr. Why patients with congestive heart failure die: arrhythmias and sudden cardiac death. Circulation 75 (Suppl 4): 2835, 1987.

4. Stevenson WG, Stevenson LW, Middlekauff HR, Saxon LA. Sudden death prevention in patient with advanced ventricular dysfunction. Circulation 88: 2953-2961, 1993.

5. Zipes DP, Libby P, Bonow RO, Braunwald E. Heart disease. In: A
Textbook of Cardiovascular Medicine. 7th ed. W. B. Saunders Company, Philadelphia, 2005: 1603-1606.

6. Kertai MD, Bountioukos M, Boersma E, et al. Aortic stnosis: an underestimated risk factor for perioperative complications in patients undergoing noncardiac surgery. Am J Med 116: 8-13, 2004.

7. Gilbert ND, LeRoy GV, Fenn FK. The effect of distention of abdominal viscera on the blood flow in the circumflex branch of the left coronary artery of the dog. Am Heart J 20: 519-524, 1940.

8. Lown B, Verrier RL. Neural activity and ventricular fibrillation. N Engl J Med 294: 1165-1170, 1976.

9. Zipes DP, Libby P, Bonow RO, Braunwald E. Heart disease. In: A Textbook of Cardiovascular Medicine. 7th ed. W. B. Saunders Company, Philadelphia, 2005: 576-577.

(C) 2008 The Japanese Society of Internal Medicine http://www.naika.or.jp/imindex.html 